International Journal of English Language and Literature Studies

$\operatorname{ISSN}(e): \quad 2306-0646$

$\operatorname{ISSN}(p): \quad 2306-9910$

DOI: 10.18488/journal.23.2021.102.185.201

Vol. 10, No. 2, 185-201.

(C) 2021 AESS Publications. All Rights Reserved.

URL: www.aessweb.com

check for
updates

\title{
EXPLORING FOREIGN LANGUAGE LEARNERS' PERCEPTIONS DURING THE NEGOTIATION OF MEANING: UNFOCUSED TASK AND FOCUSED TASK
}

\author{
Dlora ${ }^{1+}$ \\ Patuan Raja ${ }^{2}$ \\ Muhammad \\ Sukirlan ${ }^{3}$
}

\author{
${ }^{1,2, s}$ English Department, Faculty of Education, Lampung University, \\ Indonesia. \\ Emailinainggolan.flora@yahoo.com Tel: 08127972654 \\ _Emailiraja_pid@yahoo.com Tel: 082185050249 \\ 'Email:muhammad_sukirlan@yahoo.co.id Tel: 081369064895
}

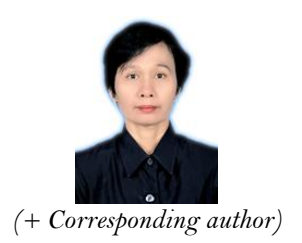

$A B S T R A C T$

Article History

Received: 19 February 2021 Revised: 26 March 2021 Accepted: 4. May 2021

Published: 2 June 2021

Keywords

Focused task

Language quality

Negotiation of meaning

Perception types of pairs

Unfocused task.

\begin{abstract}
The main objective of this study is to explore how students of the English Education Study Program at the Faculty of Education of the University of Lampung, Indonesia perceive learning, involving an unfocused task and focused task. The participants of this study were grouped in 3 pairs; high-high $(\mathrm{H}-\mathrm{H})$, high-low $(\mathrm{H}-\mathrm{L})$ and low-low $(\mathrm{L}-\mathrm{L})$ pairs. In the unfocused task, each pair was given a topic. They selected 5 from 24 available personality traits with a reason for each. While in the focused task, the discussed topics were the linguistic problems (grammar and vocabulary) coming up during the unfocused task. An adapted open-ended interview method aimed at measuring perceptions of unfocused and focused tasks served as the research instrument. The results revealed several facts about the two tasks including that the unfocused task was enjoyable to all the three types of pairs, but they failed to get input for the good of the development of their language quality because during the negotiation of meaning they focused more on meaning. Secondly, the focused task was enjoyable to $\mathrm{H}-\mathrm{H}$ and $\mathrm{H}-\mathrm{L}$ pairs for different reasons, and too difficult and stressful for the L-L pair. In other words, focused task was not appropriate for L-L pair. It is recommended that further studies involving more categories should investigate this field further.
\end{abstract}

Contribution/ Originality: This study contributes to the existing literature of negotiation of meaning to reveal what perceptions foreign language learners have about unfocused and focused tasks, particularly in acquisition of a language.

\section{INTRODUCTION}

There have been abundant studies on how learners put effort to understand and get understood by their mates while interacting in the target language, both offline (Azkarai \& Agirre, 2016; Baharun, Harun, \& Othman, 2018; Farangis, 2013; Nurazizah, Agustien, \& Sutopo, 2018; Yufrizal, 2007) and online (Arslanyilmaz \& Pedersen, 2010; Bower \& Kawaguchi, 2011; Castrillo, Monje, \& Bárcena, 2011; Thio, 2005; Yazigi \& Paul, 2005; Zhu \& Carless, 2018). Taking the terms used by Ellis (2003) i.e. unfocused task and focused task, it seems the above mentioned studies applied unfocused tasks, which were loosely bound to certain tenses. The results of their studies demonstrate that during a discussion, the learners were engaged in negotiation of meaning (NoM) in order to understand each other, and the studies also attempt to find whether this NoM benefits the learners in terms of their 
language development, since they are highly active in the discussion. Contradictory to this idea, Foster and Ohta (2005) believe that NoM does not contribute to learners' language development. Concurrently Nurazizah et al. (2018) report that Malaysian learners use Malay when they encounter any problem in expressing their ideas in English.

To the authors' best knowledge, in spite of the various studies concerning NoM, not a single study has looked into how learners perceive the discussions in unfocused and focused tasks. For this reason, this research requires to focus on the perceptions of two tasks so that deep insights into the quality of a learning model involving these two tasks can be obtained. Tavakoli (2009) and Awwad (2019) point out that it is of importance to know learners' perceptions in order to acquire deep information on the effectiveness of a learning model. Mouly (1973) had earlier affirmed that two persons with the same experience might not share the same perception.

Based on statements made by Tavakoli (2009); Awwad (2019) and Mouly (1973) on the importance of learners' perceptions and the existence of controversy over the benefit from NoM in English learning, as mentioned above, this research attempts to understand the quality of the learning involving unfocused and focused tasks from learners' point of view. Learners' perceptions may be modified with the instruments used by Mahpul (2014) in his research on learners' perceptions of the learning model of Task-based language teaching (TBLT). The perceptions were classified into five categories, i.e., Level of Difficulty, Degree of Stress, Confidence, Interest, and Motivation. In this research, there is one more category, i.e., Learning Outcomes. It was added in order to answer the controversy described above, which is over the contribution of NoM to learners' language development when they are engaged in the discussions in unfocused and focused tasks.

\section{RESEARCH QUESTIONS}

With all the studies above in mind, the authors decided to take on this research, which concerns how learners perceive a learning process when they are engaged in NoM in the discussions of unfocused and focused tasks. The research questions for this study are:

1. How do the students of the English Education Study Program at the Faculty of Education of the University of Lampung perceive the learning involving an unfocused task?

2. How do the students of the English Education Study Program at the Faculty of Education of the University of Lampung perceive the learning involving a focused task?

\section{LITERATURE REVIEW}

\subsection{Unfocused and Focused Tasks.}

Ellis (2003) infers unfocused tasks are arranged without being bound to certain tenses. This inference is in accordance with the essence of Natural Approach pioneered by Terrell (1977) which embraces the idea that in an approach of English learning, it is the natural communication skills which should be focused on and learners should be facilitated with tasks that give them chances to use the language as a means of communication in real life. Besides unfocused tasks, focused tasks in learning (which are bound to certain tenses) can also be involved, but it is rather difficult to arrange them (Ellis, 2003). In order to understand what Ellis (2003) asserts related to focused tasks, we arranged them based on the linguistic problems (of grammar and vocabulary) which had been encountered by the learners during the unfocused tasks while they were having discussions. In this way, the principle of Natural Approach crystallized by Terrell (1977) which provides learners with chances to express their ideas naturally is required and could be fulfilled. Concurrently, the principle of communicative language teaching Richards (2006), whose center is the information gap, could also be accommodated. 


\subsection{Previous Studies on Learners' Perceptions}

Ample studies on teachers' and learners' perception in the process of English learning have been conducted by several researchers. For instance, Tavakoli (2009a) researched on task difficulty in learning from the viewpoint of teachers. Ardasheva and Tretter (2012) conducted a research on English teachers' and learners' perceptions and communication strategies used in the ESL learning process. Hussain and Shiratuddin (2017) dealt with the research on teachers' perceptions of the qualities of instructional media with a digital storytelling concept. Studies on the perception of the application of Task-Based Language Teaching (TBLT) have also been commonly carried out. For instance, Révész and Gurzynski-Weiss (2016) studied how fifteen highly experienced teachers applied TBLT in their teaching. Awwad (2019) revealed that ESL teachers have different perception of task difficulty. The same applies to learners' perceptions as well due to cognitive task complexity. Lim and Hwang (2019) performed a study on Korean grown-up learners' perceptions. They found out that learners do not share the same perception of grammar accuracy. Tavakoli's (2009) study concerns task difficulty, while Fang (2015) focuses on learners' perceptions of metaphor; King and Rothman (2018) focused more on students' perception on communicative language teaching. They found that the learners like to have group work. The researchers did what they did in order to acquire in-depth information about the effectiveness of a learning model or certain teaching material.

What Ellis (2003) deduces on unfocused tasks has actually been applied and looked into by earlier researchers, by way of giving learners topics to discuss and the learners were free to express their ideas without being too much attached to certain tenses. The results lead to the understanding that during interaction, the learners were engaged in the process of NoM (Baharun et al., 2018). However, if learners find it too difficult to express their ideas in the target language, they normally use their first language, or even gestures (Nurazizah et al., 2018). This is congruent with the findings of Castrillo et al. (2011); Cook (2015); Azkarai and Agirre (2016); Hartono and Ihsan (2017) that during a discussion, learners make the effort to understand each other despite the abundant linguistic problems they produce. In other words, the learners have enough chance to practice the language, and it benefits them to develop their language (Mahpul \& Oliver, 2018).

Learning the results and findings in relation to unfocused and focused tasks above, it is safe to infer that the studies were concentrated on the researchers' perceptions, not the learners', while this research focuses on the learners' perceptions. So, it is beyond doubt reasonable to consider this research unprecedented.

\section{METHODOLOGY}

\subsection{Participants}

The population of this study comprised 34 students of the English Education Study Program at the Faculty of Education, University of Lampung, Indonesia. Six out of these 34 students, who were in the fourth semester, were chosen as participants of this research. The information on their English skills were obtained from the lecturer teaching Speaking skills. Out of the 34 students, 9 fell into the category of high proficiency learners, while 11 fell into that of low proficiency ones. As for the rest, they were of medium proficiency. The students with high levels of English were those who were able to express their ideas without any considerable problems and be understood by good listeners, while the ones with low levels were those who had trouble in expressing their ideas and made it difficult for listeners to understand them by using lengthy sentences (Heaton, 1991). The selection of six students as sample of the study considered these characteristics as the pairing was to be done based on High and Low proficiency levels.

The sampled six students had been classmates for four semesters. It was assumed that they were close friends, and during the time they spent together, they were highly engaged in discussions several times in every subject, either in groups or in pairs. Nonetheless, their levels of English varied. They were divided into three pairs for this study but before pairing, they were each given a questionnaire about which classmates were closest to them. They were asked to write five classmates' names. It was done in order that during discussions, they should feel free to 
express their ideas. The pairing was done with reference to their English proficiency and close friends. The first pair was composed of two high-proficiency students (H-H), the second comprised one high-proficiency student and one low-proficiency student (H-L), and the third had two low-proficiency students (L-L)).

\subsection{Instruments and Data Collection}

In the unfocused task, each pair was given a topic. They were required to select 5 from 24 available personality traits with a reason for each. The fundamental basis of the arrangement of the focused tasks in this research not only lay in form (meaning) which would potentially develop, but also in forms (aspects of linguistics) since the learners would get input from their output (Swain, 1985; Swain \& Lapkin, 1995). Each pair had 15 minutes for this task. While in the focused task, the discussed topics were the linguistic problems (grammar and vocabulary) coming up during the unfocused task. Following the discussions, open-ended interviews using Indonesian language were carried out so that what the students experienced in the discussions in the unfocused task was still fresh in their minds (Creswell, 1988; Creswell, 2008). All the utterances in the interviews were recorded and transcribed verbatim. Table 1 presents samples of open-ended interview protocol, adapted from Mahpul (2014).

Table-1. Open-Ended Interview Protocol.

\begin{tabular}{|c|c|c|}
\hline No & Categories & Questions \\
\hline 1 & Level of Difficulty & What do you think about learning activity? Was it easy? Why? \\
\hline 2 & Degree of Stress & $\begin{array}{l}\text { How did you feel when you were } \\
\text { during the discussion? Relaxed or stressed? Why? }\end{array}$ \\
\hline 3 & Confidence & $\begin{array}{l}\text { Did you feel confident while sharing your ideas during } \\
\text { the discussion? Why? }\end{array}$ \\
\hline 4 & Interest & $\begin{array}{l}\text { What do you think of the learning process, was it } \\
\text { interesting? Why? }\end{array}$ \\
\hline 5 & Motivation & Does such activity motivate you to learn English? Why? \\
\hline 6 & Learning outcomes & $\begin{array}{l}\text { Does such activity give you any benefits from learning English? Can you give } \\
\text { the example(s)? }\end{array}$ \\
\hline
\end{tabular}

\subsection{Data Analysis}

The interview transcriptions were read repeatedly and manually analyzed on the basis of the descriptive and NVivo coding (Miles \& Huberman, 1994; Saldana, 2009). In this research, the students' answers to the question of each perception category (Table 1) were coded and then given symbols. A tick $(\boldsymbol{\checkmark})$ means that the corresponding answer agreed with the statement of the given coding and a cross (X) means that it did not agree with it. This will be illustrated in detail later in the Results section.

\section{RESULTS}

The results of this research are described in accordance with the aforementioned research questions. The first RQ stated:

RQ 1. How do the students of the English Education Study Program at the Faculty of Education of the University of Lampung perceive the learning involving an unfocused task?

The students' perceptions of learning involving an unfocused task for each category, i.e., Level of Difficulty, Degree of Stress, Confidence, Interest, Motivation, and Learning Outcomes, are shown in Table 2. This data was obtained from the open-ended interview protocol, as described in the methodology. For the sake of validity of data, the interviews were conducted in the Indonesian language.

\subsection{Unfocused Task \\ 5.1.1. Unfocused Task: Level of Difficulty}

Q: What do you think about the learning activity? Was it easy? Why? 
As seen in the Table 2 below, some students indicated that the unfocused task was easy. The rest indicated the contrary.

Table-2. Unfocused Task: Level of Difficulty.

\begin{tabular}{l|l|c|c|c|c|c|c}
\hline No & Perceptions & \multicolumn{2}{|c|}{ H-H } & \multicolumn{2}{c|}{ H-L } & \multicolumn{2}{c}{ L-L } \\
\hline & & H1 & H2 & H & L & L1 & L2 \\
\hline & The task was easy: Reasons & & & & & & \\
\hline 1 & Familiarity with the topic & $\checkmark$ & $\checkmark$ & $\checkmark$ & $\checkmark$ & $\checkmark$ & $\checkmark$ \\
\hline 2 & Doing it with a friend & $\checkmark$ & $\checkmark$ & $\checkmark$ & $\checkmark$ & $\checkmark$ & $\checkmark$ \\
\hline & The task was difficult: Reasons & & & & & & \\
\hline 1 & Problems with the language & X & X & X & $\checkmark$ & $\checkmark$ & $\checkmark$ \\
\hline
\end{tabular}

All the pairs said that the unfocused task had been easy since it was related to their field as prospective teachers. It concerned the personality traits that every teacher should have. They also said that they had expressed their ideas spontaneously and had not been afraid of making mistakes because they were having discussions with their own friends. The students with low levels of English emphasized that the difficulty did not lie in the material, but in how to express their ideas in English.

H1-H2 Pair

- H1: (It was easy to get ideas since it suited us as prospective teachers).

- H2: (It was not difficult, ma'am, since the material was about choosing 5 from 24 personality traits a teacher should have. So, I had a lot of reasons for them.)

H-L Pair

- H: (Easy, ma'am, and the topic was nice, about personality traits a teacher should have)

- L: (The material was nice, ma'am, although it was rather difficult to express ideas in English. Sometimes, I mixed it with Indonesian.).

L1-L2 Pair

- L1: (It was not the material which was difficult, but expressing ideas in English. We used Indonesian a lot.)

- L2: (It was a bit difficult, ma'am. The material was nice, but it was just hard to express our ideas in English.)

5.1.2. Unfocused Task: Degree of Stress

Q: How did you feel when you were expressing your ideas during the discussion? Relaxed or stressed? Why?

Table-3. Unfocused Task: Degree of Stress.

\begin{tabular}{l|l|c|c|c|c|c|c}
\hline No & Perceptions & \multicolumn{2}{|c|}{ H-H } & \multicolumn{2}{c|}{ H-L } & \multicolumn{2}{c}{ L-L } \\
\hline & & H1 & H2 & H & L & L1 & L2 \\
\hline 1 & Doing it with a friend & $\checkmark$ & $\checkmark$ & $\checkmark$ & $\checkmark$ & $\checkmark$ & $\checkmark$ \\
\hline 2 & The material was interesting & $\checkmark$ & $\checkmark$ & $\checkmark$ & $\checkmark$ & $\checkmark$ & $\checkmark$ \\
\hline 3 & Using code-mixing & X & X & X & $\checkmark$ & $\checkmark$ & $\checkmark$ \\
\hline
\end{tabular}

Table 3 shows that all the pairs pointed out that during their discussions in the unfocused task, they had felt relaxed and not found the discussions stressful at all because of two reasons: first, they were having discussions with their own friends; second, the material was interesting. Besides, the low proficiency students mentioned that it was easy for them because they used the Indonesian language when they faced trouble (code-mixing). Those were the three reasons for which the pair felt relaxed during the discussions and did not find the task stressful.

H1-H2 Pair

- H1: (It was not stressful, ma'am, because we had a discussion with our own friends and the material was interesting.)

- H2: (I was happy with it, ma'am. We each put forward a lot of reasons. The topic was interesting.) 
H-L Pair

- H: (It was not stressful, ma'am, because we discussed it with friends. It was also because the topic was engaging. We had plenty of ideas to express.)

- L: (It was nice, ma'am. I found it pleasant to have a discussion about personality traits. I had a lot to talk about, though sometimes, it was too hard to say what I wanted to say in English. That was why I mixed English with Indonesian.)

L1-L2 Pair

- L1: (I did not find it stressful, ma'am. The topic was pleasant. What was rather difficult was to express our ideas in English.)

- $\quad$ L2: (It was just enjoyable, ma'am. We expressed our ideas to each other. The topic was pleasant but it is true that it was rather hard to express our ideas in English. So, we mixed English with Indonesian.)

\subsection{Unfocused Task: Confidence}

Q: Did you feel confident while sharing your ideas during the discussion? Why?

Table-4. Unfocused Task: Confidence.

\begin{tabular}{l|l|c|c|c|c|c|c}
\hline No & Perceptions & \multicolumn{2}{|c|}{ H-H } & \multicolumn{2}{|c|}{ H-L } & \multicolumn{3}{|c}{ L-L } \\
\hline & & H1 & H2 & H & L & L1 & L2 \\
\hline & Reasons for being confident & & & & & & \\
\hline 1 & $\begin{array}{l}\text { Giving the reasons for the chosen } \\
\text { personality traits }\end{array}$ & $\checkmark$ & $\checkmark$ & $\checkmark$ & $\checkmark$ & $\checkmark$ & $\checkmark$ \\
\hline 2 & Giving the reasons for disagreement & $\checkmark$ & $\checkmark$ & $\checkmark$ & $\checkmark$ & $\checkmark$ & $\checkmark$ \\
\hline
\end{tabular}

Table 4 reveals that all pairs agreed that their understanding of the topic made them confident about themselves when putting forward their ideas in discussions.

H1-H2 Pair

- H1: (I had the discussion with my own friend, ma'am, and the topic was the five characters we had each chosen from those on the worksheets, so I just found it easier to find reasons because I had many ideas of the topic.)

- H2: (The topic was interesting, so a lot of ideas to convey crossed my mind. When I disagreed to my friend's idea, I just put forward the reasons. I was not hesitant about it since the partner was my own friend.)

H-L Pair

- H: (It suited us, as prospective teachers. We shared our ideas with each other freely, spontaneously.)

- L: (Yes, I gave a lot of ideas because of a nice topic with a friend of mine. The topic was really nice and the discussion took place with a friend.)

L1-L2 Pair

- L1: (I was confident, ma'am. I put forward plentiful reasons since the topic was familiar to me.)

- L2: (I expressed abundant ideas since the topic had once been discussed in the subject Studying and Learning.)

\subsubsection{Unfocused Task: Interest}

Q: What do you think of the learning process, was it interesting? Why?

Table 5 shows that all the students' reasons centered on the suitability of the topic for them as prospective teachers. The other reasons given by the L-learners were that the reasons they had put forward were spontaneous and they had sometimes used Indonesian expressions (code-mixing) when they had trouble in expressing their ideas in English. 
Table-5. Unfocused Task: Interest.

\begin{tabular}{l|l|l|l|l|l|l|l}
\hline No & Perceptions & \multicolumn{2}{l|}{ H-H } & \multicolumn{2}{l|}{ H-L } & \multicolumn{2}{l}{ L-L } \\
\hline & & H1 & H2 & H & L & L1 & L2 \\
\hline & Reasons for being interested & & & & & & \\
\hline 1 & $\begin{array}{l}\text { The topic was suitable for the } \\
\text { learners }\end{array}$ & $\checkmark$ & $\checkmark$ & $\checkmark$ & $\checkmark$ & $\checkmark$ & $\checkmark$ \\
\hline 2 & Code-Mixing & X & X & X & $\checkmark$ & $\checkmark$ & $\checkmark$ \\
\hline
\end{tabular}

\subsubsection{Unfocused Task: Motivation}

Q: Does such activity motivate you to learn English? Why?

Table-6. Unfocused Task: Motivation

\begin{tabular}{l|l|c|c|c|c|c|c}
\hline No & Perceptions & \multicolumn{2}{c|}{ H-H } & \multicolumn{2}{c|}{ H-L } & \multicolumn{2}{c}{ L-L } \\
\hline & \multicolumn{2}{|c|}{ H1 } & H2 & H & L & L1 & L2 \\
\hline & Reasons for being motivated & & & & & & \\
\hline 1 & $\begin{array}{l}\text { Trying to express ideas in } \\
\text { English }\end{array}$ & $\checkmark$ & $\checkmark$ & $\checkmark$ & $\checkmark$ & $\checkmark$ & $\checkmark$ \\
\hline Source: & The results of open-ended interview.
\end{tabular}

Table 6 expresses that all the pairs said that they had been highly motivated in the unfocused task since they had chances to put their English knowledge into practice.

H1-H2 Pair

- H1: (Yes. I tried my best to practice my English while putting forward ideas.)

- H2: (Yes, I was happy because I had a lot of time to practice my English in the discussion.)

H-L Pair

- H: (Yes, I made considerable attempts to express my ideas in English.)

- L: (I tried desperately to be like my partner in terms of using English although, sometimes, I mixed it with Indonesian without realizing it.)

L1-L2 Pair

- L1: (Yes, ma'am, we kept trying to use English.)

- $\quad$ L2:(Though I sometimes encountered difficulty, I kept making attempts to use English.)

\subsubsection{Unfocused Task: Learning Outcomes}

Q: Does such activity give you any benefits from learning English? Can you give the example(s)?

Table-7. Unfocused Task: Learning Outcomes.

\begin{tabular}{l|l|c|c|c|c|c|c}
\hline No & Perceptions & \multicolumn{2}{c|}{ H-H } & \multicolumn{2}{c|}{ H-L } & \multicolumn{2}{c}{ L-L } \\
\hline & & H1 & H2 & H & L & L1 & L2 \\
\hline & Reasons for having good learning outcomes & & & & & & \\
\hline 1 & Getting help or corrections from the friend & $\checkmark$ & X & X & $\checkmark$ & X & X \\
\hline & Reasons for not having good learning outcomes & & & & & & \\
\hline 1 & No help or corrections from the friend & X & X & X & X & $\checkmark$ & $\checkmark$ \\
\hline
\end{tabular}

In this unfocused task, as illustrated in Table 7, all the students, either H-learners or L-learners, said that during the discussions, they had kept their minds focused on the messages conveyed by their friends. They also responded and expressed their ideas spontaneously. Their friends helped them only when they asked for it. Although they had been instructed to ask for help when they had trouble in expressing their ideas, it only took place at the beginning of the discussions and the help they needed centered on vocabulary only. However, in the 
case of the L-L pair, requests for help existed, but since neither was able to provide it, they eventually had to practice code-mixing.

H1-H2 Pair

- H1: (There was, ma'am, one word. On a worksheet, there was the word "generous". I did not know what it meant and then, I asked Ervina what it was, and she told me.)

- H2: (No, ma'am, because I just used the vocabulary I know and I know all the vocabulary on the worksheet.)

H-L Pair

- $\quad H:$ (No, ma'am, I just expressed my ideas and it seemed that my friend understood what I said.)

- L: (I asked questions in relation to the English vocabulary, like "what was 'fair' in English?" My friend told me by saying "fair". But I did not ask all the questions I had in mind. I also mixed English with Indonesian.)

L-L Pair

- L1: (I asked several questions, like "how to say someone has a talent for being a teacher," but my friend did not know either.)

- L2: (Well, we just focused on the discussion, ma'am. We mixed English with Indonesian when we had trouble with the vocabulary. So, there was no correction or help with regard to how to say something in English.)

\subsection{Focused Task}

This section discusses the findings related to $\mathrm{RQ}^{2}$ which stated:

RQ2: How do the students of the English Education Study Program at the Faculty of Education of the University of Lampung perceive the learning involving a focused task?

The steps taken in the analysis of the students' responses in the focused task were the same as those taken in the analysis of their responses in the unfocused task. The following are the results of the analysis of the data relating to their perceptions in relation to each category mentioned at the beginning of the methodology.

\subsubsection{Focused Task: Level of Difficulty}

Q: What do you think about the learning activity? Was it easy? Why?

Table-8. Focused task: Level of difficulty.

\begin{tabular}{l|l|c|c|c|c|c|c}
\hline No & Perceptions & \multicolumn{2}{|c|}{ H-H } & \multicolumn{2}{c|}{ H-L } & \multicolumn{2}{|c}{ L-L } \\
\hline & & H1 & H2 & H & L & L1 & L2 \\
\hline & The task was easy: Reasons & & & & & & \\
\hline 1 & $\begin{array}{l}\text { Being able to identify the mistakes and make } \\
\text { the corrections }\end{array}$ & $\checkmark$ & $\checkmark$ & $\checkmark$ & X & X & X \\
\hline & The task was difficult: Reasons & & & & & & \\
\hline 1 & $\begin{array}{l}\text { Being unable to identify the mistakes and or } \\
\text { correct them }\end{array}$ & X & X & X & $\checkmark$ & $\checkmark$ & $\checkmark$ \\
\hline 2 & No help was provided & X & X & X & X & $\checkmark$ & $\checkmark$ \\
\hline
\end{tabular}

Table 8 reveals that all H-learners pointed out that the focused task had been easy since the material was familiar to them, which was a discussion of grammatical mistakes. While the L-learners stated that the task had been difficult since they were not able to correct the mistakes. The L-L pair also described their difficulty in their discussion. They also complained that neither of them had been able to provide the necessary assistance in the correction of the wrong sentences so that they did not feel relaxed during the discussion.

H1-H2 pair

- H1: (It was not difficult, ma'am. After having a look at the sentences, I knew they were wrong and could put them right.) 
- H2: (I corrected an error right after I saw it, and my friend totally agreed. We shared (our ideas and knowledge to put the sentences right.)

H-L Pair

- H: (, It was not difficult, ma'am. It is true that the sentences were wrong. I also explained to Yuni why they were wrong and I made the corrections.)

- L: (Well, it had been difficult, yes, but after Nabila explained why they were wrong, I understood it.)

L-L Pair

- L1: (Yes, ma'am, it was. There were many sentences which were still too complicated for us.)

- L2: (It was difficult, ma'am. It is true that I am still weak in English.)

5.2.2. Focused Task: Degree of Stress

Q: How did you feel when you were expressing your ideas during the discussion? Relaxed or stressed? Why?

Table-9. Focused Task: Degree of Stress

\begin{tabular}{l|l|c|c|c|c|c|c}
\hline No & Perceptions & \multicolumn{2}{|c|}{ H-H } & \multicolumn{2}{|c|}{ H-L } & \multicolumn{2}{c}{ L-L } \\
\hline & & H1 & H2 & H & L & L1 & L2 \\
\hline & Reasons for not being stressed & & & & & & \\
\hline 1 & Doing it with a friend & $\checkmark$ & $\checkmark$ & $\checkmark$ & $\checkmark$ & X & X \\
\hline 2 & Being able to correct the mistakes & $\checkmark$ & $\checkmark$ & $\checkmark$ & X & X & X \\
\hline 3 & Getting explanations from the friend & $\checkmark$ & $\checkmark$ & X & $\checkmark$ & X & X \\
\hline & Reasons for being stressed & & & & & & \\
\hline 1 & The material was difficult & X & X & X & $\checkmark$ & $\checkmark$ & $\checkmark$ \\
\hline 2 & No help was provided & X & X & X & X & $\checkmark$ & $\checkmark$ \\
\hline
\end{tabular}

Table 9 exhibits the following results of all three pairs:

H-H Pair (This pair felt exciting during their discussion as they shared ideas with each other and were able to explain and make corrections to the wrong sentences.)

- H1: (Discussing the wrong sentences with a friend was nice, ma'am. We could complete each other.)

- H2: (The discussion was enjoyable, ma'am. We both thought alike of the corrections.)

H-L Pair (This pair found the discussion enjoyable as the H-learner was able to explain the corrections of the errors and the L-learner was enthusiastic about the explanations since they were so eager to understand the reasons.)

- H: (It was enjoyable, ma'am, as Yuni enthusiastically listened to my explanations.)

- L: (I found it enjoyable, ma'am. I got what Nabila explained to me. Her explanations were accompanied by other examples.)

L-L Pair (This pair felt that the focused-task discussion was stressful and uninteresting.)

- L1: (There were many errors we couldn't correct, ma'am, and in actual fact, we were doubtful of the corrections we made. None of them we were sure of.)

- L2: (It was a bit stressful, ma'am. The discussion was not nice enough, ma'am. It was complicated. Neither of us was able to explain confidently.)

\subsubsection{Focused Task: Confidence}

Q: Did you feel confident while sharing your ideas during the discussion? Why? 
Table-10. Unfocused Task: Confidence.

\begin{tabular}{l|l|c|c|c|c|c|c}
\hline No & Perceptions & \multicolumn{2}{|c|}{ H-H } & \multicolumn{2}{c|}{ H-L } & \multicolumn{2}{|c}{ L-L } \\
\hline & & H1 & H2 & H & L & L1 & L2 \\
\hline & Reasons for being confident & & & & & & \\
\hline 1 & Doing it with a friend & $\checkmark$ & $\checkmark$ & $\checkmark$ & $\checkmark$ & X & X \\
\hline 2 & Being able to explain ungrammatical sentences & $\checkmark$ & $\checkmark$ & $\checkmark$ & X & X & X \\
\hline & Reasons for not being confident & & & & & & \\
\hline 1 & Feeling doubtful & X & X & X & $\checkmark$ & $\checkmark$ & $\checkmark$ \\
\hline 2 & $\begin{array}{l}\text { Not knowing how to correct some ungrammatical } \\
\text { sentences }\end{array}$ & X & X & X & $\checkmark$ & $\checkmark$ & $\checkmark$ \\
\hline
\end{tabular}

Table 10 presents the findings of all three pairs:

H1-H2 Pair (This pair expressed their ideas confidently as they understood the material well and were friends.)

- H1: (I was just confident, ma'am. I just needed to explain why the sentences were wrong, right? It was okay to be wrong. After that, she put forward her ideas.)

- H2: (I looked at the sentences, then...ooo...this should be like this, then I told it to her. She did the same. So, we completed each other.)

H-L Pair (This pair emphasized that they had expressed their ideas confidently during the discussion for different reasons. The H-learner said that they had been confident about themself since they were able to explain why the sentences were wrong, while the L-learner said they had been confident enough to ask a question when they were doubtful of their understanding.)

- H: (I explained them to Yuni and she understood. She could also give other examples immediately when I confirmed her understanding.)

- L: (Right after Nabila explained them, I understood them all. If I had still been doubtful, I would have asked her further.)

L1-L2 Pair (This pair pointed out that they had not confidently expressed their ideas as they had not been sure about them.)

- L1: (As a matter offact, there were quite many I didn't know, ma'am. There were also those I was doubtful of.)

- L2: (Neither of us was actually sure of our ideas and we didn't even know how to correct some of them.)

\subsubsection{Focused Task: Interest}

Q: What do you think of the learning process, was it interesting? Why?

Table-11. Focused Task: Interest

\begin{tabular}{|c|c|c|c|c|c|c|c|}
\hline No & Perceptions & \multicolumn{2}{|c|}{ H-H } & \multicolumn{2}{|c|}{ H-L } & \multicolumn{2}{|c|}{$\mathbf{L}-\mathbf{L}$} \\
\hline & & H1 & $\mathrm{H} 2$ & $\mathbf{H}$ & $\mathbf{L}$ & L1 & L2 \\
\hline & Reasons for being interested & & & & & & \\
\hline \multirow[t]{2}{*}{1} & Having time to put knowledge into practice & $\checkmark$ & $\checkmark$ & $\checkmark$ & $\mathrm{X}$ & $\mathrm{X}$ & $\mathrm{X}$ \\
\hline & Reasons for being uninterested & & & & & & \\
\hline 1 & $\begin{array}{l}\text { The material was difficult and the partner could not provide } \\
\text { enough help }\end{array}$ & $\mathrm{X}$ & $\mathrm{X}$ & $\mathrm{X}$ & $\mathrm{X}$ & $\checkmark$ & $\checkmark$ \\
\hline
\end{tabular}

Table 11 exhibits the following results of all three pairs:

H1-H2 Pair (This pair said that they had eagerly engaged in the discussion since it focused on the grammatical errors they had made. Apart from it, the material suited them as prospective English teachers.)

- H1: (The material was interesting, ma'am, as it was essential for us to know as prospective teachers. We always tried to share our ideas.) 
- H2 :(Well, it was interesting since it concerned grammatical errors. So, my friend and I completed each other during the discussion.)

H-L Pair (The H-learner said that they had chances to apply their knowledge by explaining the corrections to their friend (L-learner). On the other side, their partner pointed out that grammar was important and they had got explanations from the H-learner.)

- H: (I found it interesting, ma'am. I explained to him and gave him other examples. He understood them and could make other examples as well. I had a chance to make someone understand.)

- L: (I was interested because grammar is important. My friend gave me a lot of explanations and I understood them.)

L1-L2 Pair

- L1: (I was actually interested, ma'am. I wanted to know why they were wrong, but I did not know how to correct them. So, the discussion was quite unpleasant.)

- L2: (It was difficult, ma'am. There were many errors we couldn't put right. Neither of us could.)

5.2.5. Focused Task: Motivation

Q: Does such activity motivate you to learn English? Why?

Table-12. Focused Task: Motivation

\begin{tabular}{|c|c|c|c|c|c|c|c|}
\hline \multirow[t]{2}{*}{ No } & \multirow[t]{2}{*}{ Perceptions } & \multicolumn{2}{|c|}{ H-H } & \multicolumn{2}{|c|}{ H-L } & \multicolumn{2}{|c|}{$\mathbf{L}-\mathbf{L}$} \\
\hline & & $\mathrm{H} 1$ & $\mathrm{H} 2$ & $\mathrm{H}$ & $\mathrm{L}$ & $\mathrm{L} 1$ & L2 \\
\hline & Reasons for being motivated & & & & & & \\
\hline 1 & Being aware of errors and trying to correct them & $\sqrt{ }$ & $\sqrt{ }$ & $\sqrt{ }$ & $\checkmark$ & $\checkmark$ & $\checkmark$ \\
\hline
\end{tabular}

Table 12 illustrates that all the pairs stated that they had been motivated during their discussions. Looking into the wrong sentences they had made in the unfocused task made them acquire language awareness. None of the pairs abandoned their attempt to make corrections to the sentences.

H1-H2 Pair

- H1: (We analyzed why the sentences were wrong and then corrected them.)

- H2:(We looked at the wrong sentences first and thought of the corrections.)

H-L Pair

- H: (With the activity, I paid more attention to the wrong sentences and made a determined effort to fix them.)

- L: (After being enlightened by my partner, I understood more and made a concerted effort to apply the knowledge and make other examples.)

L1-L2 Pair

- L1: (We made a serious effort to make corrections to the sentences while looking at them although we couldn't correct them all.)

- L2: (Yes, ma'am, we were more aware of errors and attempted the corrections.)

\subsubsection{Focused Task: Learning Outcomes}

Q: Does such activity give you any benefits from learning English? Can you give the example(s)?

Table 13 shows that only the $\mathrm{H} 1-\mathrm{H} 2$ and H-L pairs implied that they had acquired something for their language development, especially in terms of grammar. They were more aware of the existing errors and could remember the material they had learnt in Structure and relate the errors to it. On the other hand, L1-L2 pair actually did not get any input for their language development since no input had been obtained during their discussion as they had no ability to figure out the solutions to the discussed problems. 
Table-13. Focused Task: Learning Outcomes.

\begin{tabular}{l|l|c|c|c|c|c|c}
\hline No & Perceptions & \multicolumn{2}{|c|}{ H-H } & \multicolumn{2}{c|}{ H-L } & \multicolumn{2}{c}{ L-L } \\
\hline & & H1 & H2 & H & L & L1 & L2 \\
\hline & Reasons for having good learning outcomes & & & & & & \\
\hline 1 & Getting help or corrections from the friend & $\checkmark$ & $\checkmark$ & $\checkmark$ & $\checkmark$ & $\checkmark$ & $\checkmark$ \\
\hline & Reasons for not having good learning outcomes & & & & & & \\
\hline 1 & No help or corrections from the friend & $\checkmark$ & $\checkmark$ & X & $\checkmark$ & X & X \\
\hline
\end{tabular}

H1-H2 Pair

- H1: (When I forgot something, Ervina reminded me of it, like in the case of an adjective. We also discussed several things apart from the errors.)

- H2: (Yes, we shared with each other and it has enriched my knowledge, for instance, in the case of the subject followed by the expression "together with", whether the verb is singular or plural depends on the subject, which is before the expression.)

H-L Pair

- H: (For me, it has made me more aware of the importance of memorizing the patterns of sentences, for instance, the words "boring" and "bored". It reminded me of the lessons in the Structure class.)

- L: (A lot, ma'am. Nabila gave me a lot of good explanations. I have understood that sentences with an adjective require "to be". I have also understood the patterns and senses of conditional sentences.)

L1-L2 Pair

- L1: (There is, ma'am, but only a little and I am still doubtful of it. My friend was not sure about his ideas.)

- L2: (When we were putting effort into doing the assignment, we found out that we were unable to fix numerous sentences. We were so confused.)

\section{DISCUSSION}

\subsection{Unfocused Task}

The results of this research lead to the fact that all pairs implied that they perceived the category of level of difficulty of the unfocused task as low since the topic had been familiar to them. The perceptions related to this category were positively related to those of other categories, i.e., Degree of Stress, Confidence, Interest, and Motivation. The pairs felt relaxed since they were engaged in discussions with their friends. They also confidently expressed their ideas as the topic was easy and interesting. This goes with the idea that positive perceptions of motivation result in positive effects on language learners' success (Rehman, Bilal, Sheikh, Bibi, \& Nawaz, 2014) and Weda, Abdul Samad, Patak, and Fitriani (2018). The results also demonstrate that all the pairs did their best to understand and to be understood during their interaction. It is in support of what multiple previous researchers found out (Arslanyilmaz \& Pedersen, 2010; Azkarai \& Agirre, 2016; Baharun et al., 2018; Bower \& Kawaguchi, 2011; Castrillo et al., 2011; Farangis, 2013; Nurazizah et al., 2018; Thio, 2005; Yazigi \& Paul, 2005; Yufrizal, 2007; Zhu \& Carless, 2018) that learners make efforts to smoothen up their communication, which they call negotiation of meaning (NoM).

In this research, all the pairs spontaneously expressed their ideas. With reference to their statements on the unfocused task, the suggestion put forward by Terrell (1977) and Richards (2006) is proven right that language learners should be given some room for naturally expressing their ideas. Nonetheless, it appears that the learning process in the unfocused task did not give adequate positive effect on the development of the learners' language quality as they just made use of what they had got. In spite of the instruction that they all should make a correction or give help only when there was a linguistic problem, it seems only the H-L pair practiced this, but only at the beginning of the discussion. The violation was done by the L-learner. This L-learner asked the H-learner for assistance even when they should not. In this case, Swain's (1985) theory of the output hypothesis, that it is also 
possible for learners to get input from their own output, was in play. It was what happened to the L-learner of the H-L pair. The learners did not make corrections or provide help since they focused on the conveyed messages. The L-learner of the H-L pair and the L-learner of the L-L pair involved more code mixing. This result is in congruence with what Nurazizah et al. (2018) revealed in the context of Malaysian learners who often used Malay when they encountered trouble in expressing their ideas in English.

Given the fact that the learners practiced code-mixing and there were no solutions to the linguistic problems during the discussions, it is of very small chance that there was some development of the learners' language quality in the unfocused task. Hence it confirms what (Foster \& Ohta, 2005) inferred that during interaction, learners engage in NoM but this engagement does not make any contribution to their language development.

Putting the results of the interviews into perspectives, supported by the transcripts of the learners' dialogues in the unfocused task, it is known that only the H1-learner of the H1-H2 pair got something new, which was in respect of vocabulary, and it was just one word. It happened since they did not know the meaning of the word generous on a worksheet of theirs. The partner (H2-learner) provided the necessary help as the H1-learner asked for it. With respect to the H-L pair, the H-learner stated that they had talked spontaneously and only focused on the conveyed messages. While the L-learner requested for their partner's assistance in respect of vocabulary at the beginning of the discussion only. In view of this, it is safe to say that the L-learner's vocabulary developed only a bit as they applied code-mixing more than the H-learner provided help or made a correction.

Despite the L-learner's, of the H-L pair, low language development, the topic of the unfocused task well suited the learners' characters, which is unarguably highly advisable in a learning process. It probably drives learners' motivation to put effort into expressing their ideas in English a lot higher. Although the learners only put into practice the language knowledge they had got, in other words, without learning anything new first, they still benefited from the activity since they had ample chances to refresh their minds about what they had got, and therefore, to prolong the retention of the knowledge. By repeatedly practicing what they have got, learners will be more and more accustomed to using it spontaneously. Therefore, in order to optimize the contribution of the unfocused task to learners' language development, it is of paramount importance to form pairs or groups composed of learners with different levels of proficiency. It is noteworthy here to instruct them to request for assistance when they have trouble in expressing their ideas is as essential.

\subsection{Focused Task}

As described above, the focused task in this research was to discuss the linguistic problems the students had produced in their unfocused-task discussions. The result in this respect bears the implication that each pair had different perceptions relating to the categories. For the category level of difficulty, all the H-learners stated that this task had been easy. This category was not at all contrastive to the other perception categories, i.e. Degree of Stress, Confidence, Interest, and Motivation, in terms of how the students perceived them. With reference to the transcripts of their dialogues, it was felt that the learners felt relaxed since they had the discussions with their own friends, which also caused them to be confident in themselves while expressing their ideas. They also found the task easy and interesting. The $\mathrm{H}-\mathrm{H}$ pair said that they had shared ideas with each other during the discussion. They even discussed some material which was actually beyond the subject, "Yes, we shared with each other and it has enriched our knowledge, for instance, in the case of the subject followed by the expression "together with", whether the verb is singular or plural depends on the subject, which is before the expression.)

The sentence having together with after its subject was produced by the H1-learner and then elucidated by the H2-learner. Considering the existing data, it is a sound inference that the output hypothesis proposed by Swain (1985) played a role here as the H1-learner got knowledge (input) owing to their own utterance (output). In line with this, Kung (2013) stated that Taiwan learners who have moderate English proficiency like to have English as a medium instruction since it can motivate them to learn more English. 
The H-learner of the H-L pair stated something similar, saying that the focused task had been easy. He could even provide explanations and example sentences which eventually resulted in the partner's (L-learner) right understanding of the matter. This result is particularly in favor of Petraki and Gunawardena (2015) who stated in the case of Sri Lankan learners that they liked explicit grammar teaching.

As for the L-L pair, they shared the perception that the focused task (in the form of the discussion about the linguistic problems that they had produced during their unfocused-task discussion) was difficult. The pair admitted that they had not been able to correct the mistakes. It was this fact which caused this pair to admit that they had been stressed, unconfident, and had found the material dull. They, nonetheless, affirmed that they had been motivated to make corrections to several sentences though they were still doubtful about the corrections.

In view of the results of the interviews and the transcripts of the students' utterances, it is plausible to believe that the L-learner of the H-L pair acquired a lot of input as the H-learner gave such clear explanations and examples that the L-learner had adequate comprehension of the related points.

L: (A lot, ma'am. Nabila provided me with a lot of splendid explanations. I now understand that we need a verb to be for a sentence containing an adjective. Her explanations also concerned the patterns and meanings which conditional clauses bear.)

In the H1-H2 pair's case, they were motivated to be engaged in the learning activity with the focused task at its core as it contributed a good deal to their language awareness, as implied by the following excerpt:

H1: (We tried to analyze why the sentences were wrong and then made the corrections after we found out the reasons.)

H2: (We first looked into the wrong sentences and then figured out how to correct them.)

All the students confirmed that the focused task drove them to better awareness of English grammar. Hence, it is not baseless to say that this task is capable of intensifying learners' language awareness. This result is downright supportive of Ellis's (2002) deduction that one of the ways of heightening learners' awareness is to provide them with sufficient time to analyze linguistic problems in various forms. Concurrently, Saenz (2016) believes that education occurs when learners have awareness of the language they are learning, and it is expected that they also have curiosity about the language. In this research, the L-L pair said that they had been curious about why the sentences were wrong, yet they were not able to figure out the answers since they had no knowledge of it. Concisely speaking, this confirms that awareness alone is not enough for learners' language development. It needs to be accompanied by the ability to find out solutions to problems. For this reason, for the good of learners' language development, making pairs or groups of students with various levels of proficiency is at par with other fundamental steps.

From the interviews and transcripts, it is known that only the H1-H2 pair used English to the full during their discussion. As regards the H-L pair, their discussion was dominated by the Indonesian language. The H-learner confirmed that they had spoken Indonesian most of the time with the intention of being understood better by their partner (L-Learner) when elaborating on why the sentences were wrong and what the right ones were. The L1-L2 did something similar, but they communicated in English much less than the previous pair. They, nevertheless, still regarded the discussion as frustrating since they could not satisfy their curiosity about why the sentences were wrong.

By and large, from the perspective of the learning outcomes, the focused task was favorable to the $\mathrm{H} 1-\mathrm{H} 2$ and H-L pairs. For the former, they were able to be more aware of linguistic problems and find the solutions. Considering what they stated, the H-learner of the latter pair got such benefits as well. With regard to the third type of pair (L1-L2), it is fair enough to gather that during the focused task, they tended to feel stressed because the material was too difficult for them and neither provided assistance in the process.

\section{CONCLUSION}

Unfocused and focused tasks in English learning both have advantages and weaknesses. In this research carried out in Indonesian perspective, as befitted the learners' characters, the topic of the unfocused-task discussion was 
personality traits, so that the pairs, though their levels of proficiency were different, were all achingly enthusiastic about the expression of their ideas. They confidently expressed their ideas in English in a spontaneous manner, though some of them had to involve code-mixing using the Indonesian language. However, they did not pay enough attention to linguistic problems. The L-learners did code-mix so often that they acquired almost no input for the good of their language development from this task. Apropos of the focused task (which comprised the discussions about the linguistic problems they had produced in the unfocused task), it was of high suitability for the $\mathrm{H}-\mathrm{H}$ and $\mathrm{H}-$ L pairs. The H-learners had such decent language awareness that they could solve or explained the linguistic problems. The L-learner of the H-L pair acquired considerable input for the development of their grammar quality as their partner (H-learner) provided explicit explanations, which were also accompanied by code-mixing. On the contrary, the focused task was ill-suited for the L-L pair since it drove them to stress. In consideration of the interview, the learners of this type should be paired or grouped with learners of, at least, decent proficiency.

The researchers strongly recommend further studies be conducted in relevance to these findings. It is our expectation that researchers for whom this sphere is of interest will be engaged in deeper and more holistic approaches to these factors for better comprehension. As apparent as it seems, more studies are also paramount to in-depth understanding of to what extent these two types of tasks can benefit learners in fields other than those included in this research.

Funding: This study received no specific financial support.

Competing Interests: The authors declare that they have no competing interests.

Acknowledgement: All authors contributed equally to the conception and design of the study.

\section{REFERENCES}

Ardasheva, Y., \& Tretter, T. R. (2012). Perceptions and use of language learning strategies among ESL teachers and ELL s. TESOL Journal, 3(4), 552-585. Available at: https://doi.org/10.1002/tesj.33.

Arslanyilmaz, A., \& Pedersen, S. (2010). Enhancing negotiation of meaning through task familiarity using subtitled videos in an online TBLL environment. Turkish Online Journal of Educational Technology, 9(2), 64-77.

Awwad, A. (2019). L2 learners' and professionals' perceptions of cognitive task complexity: Towards developing an index of task difficulty. Journal of Asia TEFL, 16(2), 468-484. Available at: https://doi.org/10.18823/asiatefl.2019.16.2.2.468.

Azkarai, A., \& Agirre, I. (2016). Negotiation of meaning in child EFL learners mainstream and content and language integrated learning (CLIL). TESOL Quartterly, 5O(4), 844-851.

Baharun, H., Harun, H., \& Othman, J. (2018). Anaysis of negotiation episodes in foreign language learner interactions. GEMA Online Journal of Language Studies, 18(2), 202-2 16. Available at: https://doi.org/10.17576/gema-2018-1802-14.

Bower, J., \& Kawaguchi, S. (2011). Negotiation of meaning and corrective feedback in Japanese/English eTandem. Language Learning \& Technology, 15(1), 41-71.

Castrillo, M., Monje, E. M., \& Bárcena, E. (2011). New forms of negotiating meaning on the move: The use of mobile-based chatting for foreign language distance learning. IADIS International Journal on WWW/Internet, 12(2), 51-67.

Cook, J. (2015). Negotiation of meaning and feedback among language learners. Journal of Language Teaching and Research, 6(2), 250-257. Available at: https://doi.org/10.17507/jltr.0602.02.

Creswell, J. W. (1988). Qualitative inquiry and research design. Choosing among five traditions. USA: Sage Publications.

Creswell, J. W. (2008). Educational research: Planning, conducting, and evaluating quantitative and qualitative research (3rd ed.). Upper Saddle River, N.J: Pearson Merrill Prentice Hall.

Ellis, R. (2002). Grammar teaching: Practice or consciousness-raising? In J.C. Richards \& W.A. Renandya (Eds.), Methodology in language teaching: An anthology of current practice (pp. 167-174). Cambridge: Cambridge University Press.

Ellis, R. (2003). Task-based language learning and teaching. Oxford: Oxford University Linguistics. 
Fang, S. (2015). College EFL learners' metaphorical perceptions of english learning. The Journal of Asia Tefl, 12(3), 61-79. Available at: http://dx.doi.org/10.18823/asiatefl.2015.12.3.3.61.

Farangis, S. (2013). The effect of negotiation on second language acquisition. Education Journal, 2(6), 236-241. Available at: https://doi.org/10.11648/j.edu.20130206.15.

Foster, P., \& Ohta, A. S. (2005). Negotiation for meaning and peer assistance in second language classrooms. Applied Linguistics, 26(3), 402-430. Available at: https://doi.org/10.1093/applin/amio14.

Hartono, R., \& Ihsan, D. (2017). An analysis of meaning negotiation strategies used in conversation by undergraduate efl students. Paper presented at the Advances in Social Science, Education and Humanities Research (ASSEHR) Ninth International Conference on Applied Linguistics (CONAPLIN 9).Atlantis Press.

Heaton, J. B. (1991). Writing English language test. New York: Longman Inc.

Hussain, H., \& Shiratuddin, N. (2017). Perceptions of designers (teachers) on the quality of guidelines for the development of teaching media with the concept of digital storytelling for touch screen tablets. Malaysian Journal of Learning and Instruction, 14(2), 271-292.

King, R., \& Rothman, J. (2018). Students' perceptual learning styles and attitudes toward communicative language teaching. TESOL International Journal, 13(4), 104-120.

Kung, F.-W. (2013). The more the merrier? Bilingualism in an academic perspective: Exploring the implementation of Englishmedium instruction in Taiwanese tertiary education. Asian EFL Journal, 15(4), 8-36.

Lim, I., \& Hwang, J. (2019). Korean adult english learners' perceptions of the common grammatical features of english as a lingua franca. The Journal of Asia TEFL, 16(3), 876-893. Available at: http://dx.doi.org/10.18823/asiatefl.2019.16.3.7.876.

Mahpul. (2014). Task difficulty in dialogic oral production by Indonesian Efl learners. Perth: Curtin University. Unpublished Thesis.

Mahpul, \& Oliver, R. (2018). The effect of task complexity in dialogic oral production by Indonesian learners. Asian EFL Journal, 20(6), 33-65.

Miles, M. B., \& Huberman, A. M. (1994). Qualitative data analysis: An expanded source book (2nd ed.). Thousand Oaks, CA: SAGE.

Mouly, G. J. (1973). Psychology for effective teaching. New York: Holt Rinehart and Winston.

Nurazizah, N., Agustien, H., \& Sutopo, D. (2018). Learners's ability to negotiate meaning in interactional conversation. ELT Forum: Journal of English LanguageTeaching, 7(1), 15-23. Available at: https://doi.org/10.15294/elt.v7i1.25300.

Petraki, E., \& Gunawardena, M. (2015). The key ingredients of an effective grammar lesson: Perceptions from high school ESL students. Asian EFL Journal, $17(3), 59-84$.

Rehman, A., Bilal, H., Sheikh, A., Bibi, N., \& Nawaz, A. (2014). The role of motivation in learning English language for Pakistani learners. International Journal of Humanities and Social Science, 4(1), 254-258.

Révész, A., \& Gurzynski-Weiss, L. (2016). Teachers' perspectives on second language task difficulty: Insights from think-alouds and eye tracking. Annual Review of Applied Linguistics, 36, 182-204. Available at: https://doi.org/10.1017/s0267190515000124.

Richards, J. C. (2006). Communicative language teaching today. United States of America: Cambridge University Press 2006.

Saenz, D. M. C. (2016). Exploring language awareness in EFL second grades. Thesis: Universidad Distrital Fransisco Jose De Caldas.

Saldana, J. (2009). The coding manual for qualitative researchers. London: Sage.

Swain, M. (1985). Communicative competence: Some roles of comprehensible input and comprehensible output in its development. In Susan M. Gass and Carolyn G Madden, Eds., Input in second langauge acquisition (pp. 235-253). Rowley, MA: Newbury House.

Swain, M., \& Lapkin, S. (1995). Problems in output and the cognitive processes they generate: A step towards second language learning. Applied Linguistics, 16 (3), 371-391. Available at: https://doi.org/10.1093/applin/16.3.371.

Tavakoli, P. (2009). Investigating task difficulty: Learners' and teachers'perceptions. International Journal of Applied Linguistics, 19(1), 1-25. 
Terrell, T. D. (1977). A natural approach to second language acquisition and learning. The Modern Language Journal(61), 325337.

Thio, L. (2005). Negotiation of meaning in communicative tasks. Indonesian JELT, 1(1), 45-63.

Weda, S., Abdul Samad, I., Patak, A. A., \& Fitriani, S. S. (2018). The effects of self-efficacy belief, motivation, and learning strategies on students' academic performance in English in higher education. The Asian EFL Journal Quarterly, 2O(9.2), $140-168$

Yazigi, R., \& Paul, S. (2005). Sharing time with young learners. TESL-EJ. Teaching English as a Second or Foreign Language, 9(3), $1-26$.

Yufrizal, H. (2007). Negotation of meaning by Indonesia EFL learners. Bandung: PustakaRekaCipta, 2007.

Zhu, Q., \& Carless, D. (2018). Dialogue within peer feedback processes: Clarification and negotiation of meaning. Higher Education Research \& Development, 37(4), 883-897. Available at: https://doi.org/10.1080/07294360.2018.1446417. 